\title{
Lipid profile
}

National Diabetes Information Clearinghouse (NDIC)

\section{Definitions}

Cholesterol

Defined by National Diabetes Information Clearinghouse (NDIC)

Triglyceride

Defined by National Diabetes Information Clearinghouse (NDIC)

HDL cholesterol

Defined by National Diabetes Information Clearinghouse (NDIC)

LDL cholesterol

Defined by National Diabetes Information Clearinghouse (NDIC)

Cardiovascular disease

Defined by National Diabetes Information Clearinghouse (NDIC)

\section{Source}

National Diabetes Information Clearinghouse (U.S.). (2009). The diabetes dictionary. [Bethesda, Md.]: U.S. Dept. of Health and Human Services, National Institutes of Health, National Institute of Diabetes and Digestive and Kidney Diseases, National Diabetes Information Clearinghouse.

A blood test that measures total cholesterol, triglycerides, and HDL cholesterol. LDL cholesterol is then calculated from the results. A lipid profile is one measure of a person's risk of cardiovascular disease. 